\title{
HUBUNGAN ANTARA TINGKAT KEPATUHAN MINUM OBAT ANTIPLATELET ASPIRIN DENGAN KEJADIAN STROKE ISKEMIK BERULANG DI RS BETHESDA YOGYAKARTA
}

\author{
THE CORRELATION BETWEEN COMPLIANCE MEDICATION \\ OF ANTIPLATELET DRUGS ASPIRIN WITH RECURRENT \\ ISCHEMIC STROKE AT BETHESDA HOSPITAL IN \\ YOGYAKARTA
}

\begin{abstract}
I Dewa Gde Rainey Chrisananta Putra, Rizaldy Taslim Pinzon, Esdras Ardi Pramudita
\end{abstract}

Fakultas Kedokteran Universitas Kristen Duta Wacana Yogyakarta

Email: drpinzon17@gmail.com

\begin{abstract}
ABSTRAK
Stroke menduduki urutan ketiga terbesar penyebab kematian setelah penyakit jantung dan kanker, dengan laju mortalitas $18 \%$ sampai $37 \%$ untuk stroke pertama dan $62 \%$ untuk stroke berulang. Diperkirakan $25 \%$ orang yang sembuh dari stroke yang pertama akan mendapatkan stroke berulang dalam kurun waktu 5 tahun. Stroke berulang merupakan stroke yang terjadi lebih dari satu kali. Ketidakpatuhan minum obat memberikan peluang untuk terjadinya stroke berulang 4,39 kali dibandingkan dengan penderita stroke yang teratur berobat. Tujuan penelitian ini untuk melihat hubungan antara tingkat kepatuhan minum obat anti-platelet aspirin dengan kejadian stroke iskemik berulang digunakan penelitian analitik dengan metode kasus kontrol. Penelitian menggunakan sampel sebanyak 112 data yang diambil dari data primer pasien. Kelompok kasus sebanyak 56 pasien stroke berulang dan kelompok kontrol sebanyak 56 pasien stroke tidak berulang dengan menanyakan riwayat stroke dan kepatuhan minum obat aspirin tahun 2016 kebelakang. Analisis terhadap 112 subyek yang memenuhi kriteria penelitian menunjukkan bahwa terdapat hubungan antara tingkat kepatuhan sedang dan rendah minum obat anti-platelet Aspirin dengan kejadian stroke iskemik berulang dengan $p>0,05$ (OR : 28,52, 95\% CI: 12,65788,762, $p$ : $<0,001)$ Hasil menunjukkan bahwa terdapat hubungan antara tingkat kepatuhan minum obat anti-platelet aspirin dengan kejadian stroke iskemik berulang di Rumah Sakit Bethesda Yogyakarta.
\end{abstract}

Kata kunci : Stroke, kepatuhan minum obat antiplatelet aspirin 


\begin{abstract}
Stroke is the third leading cause of death after heart disease and cancer, with a mortality rate of $18 \%$ to $37 \%$ for the first stroke and $62 \%$ for recurrent stroke . An estimated $25 \%$ of people who recover from the first stroke will get recurrent stroke within 5 years. Recurrent stroke is a stroke that occurred more than once. Noncompliance taking medication provides an opportunity for the occurrence of recurrent stroke by 4.39 times compared with patients on a regular stroke treatment. Aim of this study to observe the correlation between compliance medication of antiplatelet medication (low dose aspirin) with recurrent ischemic stroke. This study used method which was analytical research with case-control methodology. This study used 112 samples from primary data of patients. Case group was 56 of recurrent stroke patients and control group was 56 patients with no recurrent stroke by asking a history of stroke and medication adherence Aspirin 2016 backward. Analysis from 112 samples which fulfilled all the criteria in this research indicate that there is a correlation between compliance medication with middle and low adherence of anti - platelet aspirin with recurrent ischemic stroke incidence with $p>0.05$ (OR : 28,52, 95\% CI: 12,657-88,762, p: < 0.001). Result indicates that there is a correlation between compliance medication of anti - platelet aspirin with recurrent ischemic stroke at Bethesda Hospital in Yogyakarta.
\end{abstract}

Keywords : Stroke, compliance of aspirin antiplatelet medication

\title{
PENDAHULUAN
}

Stroke atau cedera serebrovaskular adalah berhentinya suplai darah ke bagian otak sehingga mengakibatkan hilangnya fungsi otak. Hal ini dapat terjadi karena pecahnya pembuluh darah atau terhalanginya asupan darah ke otak oleh gumpalan. Terhambatnya penyediaan oksigen dan nutrisi ke otak menimbulkan masalah yang serius karena dapat menimbulkan kecatatan fisik mental bahkan kematian (World Health Organization Stroke, 2010).

Menurut studi Framingham, insiden stroke berulang dalam kurun waktu 4 tahun pada pria $42 \%$ dan wanita $24 \%$. Mendapatkan kejadian stroke berulang $29,52 \%$ yang paling sering terjadi pada usia 60 - 69 tahun $(36,5 \%)$, dan pada kurun waktu 1- 5 tahun $(78,37 \%)$ dengan faktor risiko utama adalah hipertensi $(92,7 \%)$ dan dislipidemia $(34,2 \%)$ (Fauci, 2008). 
Kepatuhan merupakan hal yang sangat penting terutama pada pengobatan jangka panjang. Sangatlah penting bagi farmasis memperhatikan pasien dalam hal kepatuhan dalam mengonsumsi obat agar tercapai target dari terapi. Menurut laporan WHO pada tahun 2003, kepatuhan rata-rata pasien pada terapi jangka panjang terhadap penyakit kronis di negara maju hanya sebesar 50\% sedangkan di negara berkembang, jumlah tersebut bahkan lebih rendah. Kepatuhan pasien sangat diperlukan untuk mencapai keberhasilan terapi utamanya pada terapi penyakit tidak menular (World Heart Federation, 2014).

Berdasarkan data yang telah dijelaskan diatas, dengan memperhatikan banyaknya kasus stroke, khususnya stroke iskemik yang berulang, maka menandakan begitu pentingnya terapi penanganan stroke iskemik. Sebagian besar penderita stroke iskemik berisiko untuk terserang kembali, maka diperlukan upaya pencegahan terjadinya kejadian stroke berulang yaitu salah satunya dengan pencegahan dan penatalaksanaan menggunakan obat antiplatelet aspirin yang diberikan pada pasien paska serangan stroke iskemik (Fitzsimmons, 2007).

Sesuai dengan guideline yang dikeluarkan oleh ASA (American Stroke Association) pada tahun 2010 tentang pencegahan rekurensi pada pasien stroke iskemik yang menyatakan bahwa agen antiplatelet yang salah satunya merupakan aspirin dapat mengurangi risiko rekurensi stroke iskemik sebesar $15 \%$ dibandingkan dengan placebo (American Stroke Association, 2010).

Penelitian yang dilakukan oleh Duke Clinical Research Institute tentang ketidakpatuhan minum obat antiplatelet menemukan bahwa hampir 20 persen pasien telah berhenti mengambil satu atau lebih obat yang diresepkan untuk mereka, sementara 3,5 persen pasien tidak mengambil obat mereka di tiga bulan (Duke Clinical Research Institute, 2010). Penelitian ini bertujuan untuk mengukur hubungan tingkat kepatuhan konsumsi antiplatelet aspirin dengan kejadian stroke iskemik berulang.

\section{METODE PENELITIAN}

Data yang digunakan dalam penelitian ini adalah data pada bulan Mei 2016 sampai dengan Juni 2016 yang diambil dari data primer pasien RS Bethesda 

Yogyakarta. Jumlah sampel dalam penelitian ini berjumlah 112 data yang terbagi menjadi 56 data kelompok kasus dan 56 data kelompok kontrol.

Rancangan yang dilakukan dalam penelitian ini adalah menggunakan metode penelitian uji analitik dengan menggunakan desain studi kasus-kontrol (case-control study). Sampel penelitian ini adalah populasi penderita stroke berulang yang menjalani pengobatan antiplatelet pada tahun 2016 kebelakang dan memenuhi kriteria inklusi. Kriteria kasus yang menjadi kriteria inklusi adalah pasien stroke iskemik berulang pada tahun 2016 kebelakang yang terdiagnosis oleh dokter dengan hasil CT Scan kepala dan memiliki data rekam medis lengkap yang sedang menjalani terapi pengobatan dengan antiplatelet aspirin di RS Bethesda, Yogyakarta. Kriteria ekslusi penelitian ini adalah pasien stroke iskemik yang tidak bisa berkomunikasi dengan baik. Pasien stroke iskemik berulang yang menolak untuk diwawancarai.

Besar sampel pada penelitian ini diukur menggunakan besar proporsi. Berdasarkan rumus besar sampel yang dihitung dengan program komputerisasi, didapatkan jumlah sampel sebesar pasien untuk populasi kasus sebesar 51 pasien dan untuk populasi kontrol sebesar 51. Diperkirakan adanya drop out pasien sebesar $10 \%$, dengan demikan jumlah sampel total adalah 112 pasien.

Pada pelaksanaan penelitian, data yang digunakan adalah data primer dengan wawancara langsung kepada pasien. Setelah mendapatkan pasien dengan kriteria inklusi yang sudah ditentukan, dilanjutkan dengan proses wawancara dengan bertanya sesuai dengan kuisioner yang sudah dibuat. Kriteria kasus sasaran wawancara adalah pasien dengan stroke iskemik berulang dan menggunakan antiplatelet aspirin, sedangkan pada kriteria kontrol merupakan pasien stroke iskemik tidak berulang dan menggunakan antiplatelet aspirin. Data yang sudah didapatkan selanjutnya akan dianalisis menggunakan analisis univariat, bivariat dan multivariat.

\section{HASIL DAN PEMBAHASAN}

Hasil analisis deskriptif seperti tersaji pada Tabel I menunjukan dari 112 pasien, rentang usia pasien yang paling banyak menderita stroke adalah adalah 
usia 41-60 tahun yaitu sebanyak 57 pasien $(50,9,1 \%)$. Pasien yang paling banyak menderita stroke adalah laki-laki yaitu sebesar 76 pasien (67,9\%). Pasien yang memiliki riwayat hipertensi sebesar 112 pasien (100\%) dan pasien yang memiliki riwayat diabetes mellitus sebesar 92 pasien $(82,1 \%)$. Durasi pemberian obat pada pasien yang paling banyak adalah pasien dengan durasi pemberian diatas 12 bulan sebesar 65 pasien (58\%). Hasil tersebut juga memperlihatkan bahwa tingkat kepatuhan pada pasien adalah berada pada tingkat kepatuhan rendah dan sedang yaitu sebanyak 61 pasien $(54,5 \%)$.

Berdasarkan hasil analisis pada Tabel II, dengan menggunakan uji Chisquare terdapat variabel yang menunjukan hubungan yang signifikan, hal ini dikarenakan nilai $p$ pada analisis bivariat kurang dari 0,05 , yaitu durasi pemberian obat > 12 bulan (OR : 6,03, 95\% CI: 2,459 - 12,806, p: <0,001), dan tingkat kepatuhan minum obat rendah dan sedang (OR : 28,52, 95\% CI: 12,657-88,762, p: $<0,001)$.

Analisis bivariat dilakukan untuk menguji apakah ada hubungan yang signifikan antara variabel perancu dengan variabel tergantung, tersaji pada Tabel III dan hasilnya terdapat dua variabel perancu yang memiliki hubungan signifikan dengan variabel tergantung. Hasil analisis bivariat untuk variabel yang bermakna selanjutnya diteruskan dengan analisis multivariat dengan regresi logistik dan hasilnya menunjukan bahwa terdapat variabel-variabel yang berhubungan dengan kejadian stroke berulang pada pasien stroke iskemik, yang mana hal tersebut adalah durasi pemberian obat $>12$ bulan (OR : 6,03, 95\% CI: 2,459-12,806, $p$ : $<0,001$ ), dan tingkat kepatuhan minum obat rendah dan sedang (OR : 28,52, 95\%CI: 12,657-88,762, p: <0,001).

Nilai OR pada durasi minum obat dan tingkat kepatuhan minum obat rendah dan sedang bernilai lebih dari 1 artinya faktor tersebut berhubungan dengan kejadian stroke berulang pada pasien stroke iskemik. Nilai OR pada pasien dengan durasi minum obat lebih dari 12 bulan memiliki risiko 6 kali lebih tinggi dibandingkan dengan pasien yang memiliki durasi yang kurang dari 12 bulan. Tingkat kepatuhan minum obat rendah dan sedang juga memiliki nilai OR lebih 
dari 1, yang artinya bahwa pasien dengan tingkat kepatuhan minum obat rendah dan sedang memiliki risiko 28 kali lebih tinggi dibandingkan dengan pasien yang memiliki tingkat kepatuhan tinggi untuk mengalami stroke berulang. Hal tersebut menandakan bahwa tingkat kepatuhan minum obat rendah dan sedang merupakan suatu faktor terhadap kejadian stroke berulang pada pasien stroke iskemik.

Tabel I. Karakteristik Dasar Pasien

\begin{tabular}{|c|c|c|}
\hline Karakteristik Pasien & $n=112$ & $\%$ \\
\hline \multicolumn{3}{|l|}{ Jenis kelamin } \\
\hline Laki-laki & 76 & $67,9 \%$ \\
\hline Perempuan & 36 & $32,1 \%$ \\
\hline \multicolumn{3}{|l|}{ Usia } \\
\hline 41-60 tahun & 57 & $50,9 \%$ \\
\hline 61-70 tahun & 55 & $49,1 \%$ \\
\hline \multicolumn{3}{|l|}{ Stroke berulang } \\
\hline Ya & 56 & $50 \%$ \\
\hline Tidak & 56 & $50 \%$ \\
\hline \multicolumn{3}{|l|}{ Riwayat DM } \\
\hline Ya & 92 & $82,1 \%$ \\
\hline Tidak & 20 & $17,9 \%$ \\
\hline \multicolumn{3}{|l|}{ Riwayat penyakit jantung dan pembuluh darah } \\
\hline $\mathrm{Ya}$ & 54 & $48,2 \%$ \\
\hline Tidak & 58 & $51,8 \%$ \\
\hline \multicolumn{3}{|l|}{ Merokok } \\
\hline Ya & 68 & $48,2 \%$ \\
\hline Tidak & 44 & $39,3 \%$ \\
\hline \multicolumn{3}{|l|}{ Durasi Pemberian Obat } \\
\hline$<12$ Bulan & 47 & $42 \%$ \\
\hline$>12$ Bulan & 65 & $58 \%$ \\
\hline \multicolumn{3}{|c|}{$\begin{array}{l}\text { Tingkat kepatuhan minum obat menggunakan Morisky } \\
\text { Medication Adherence Scale: }\end{array}$} \\
\hline Kepatuhan rendah dan sedang & 61 & $54,5 \%$ \\
\hline Kepatuhan tinggi & 51 & $45,5 \%$ \\
\hline
\end{tabular}


Tabel II. Hubungan Antara Faktor Prediktor Kepatuhan Minum Obat Dengan Variabel Tergantung

\begin{tabular}{|c|c|c|c|c|c|}
\hline Variabel & $\begin{array}{l}\text { Stroke } \\
\text { Berulang }\end{array}$ & $\begin{array}{c}\text { Stroke } \\
\text { Tidak } \\
\text { Berulang } \\
\end{array}$ & OR & $\begin{array}{c}95 \% \\
\text { CI }\end{array}$ & $\boldsymbol{P}$ \\
\hline \multicolumn{6}{|l|}{ Jenis kelamin } \\
\hline Perempuan & 19 & 17 & Ref & & \\
\hline Laki-laki & 37 & 39 & 0,84 & $0,533-2,606$ & 0,686 \\
\hline \multicolumn{6}{|l|}{ Usia } \\
\hline $41-60$ tahun & 24 & 33 & Ref & & \\
\hline $61-70$ tahun & 32 & 23 & 1,91 & $0,947-2,017$ & 0,129 \\
\hline \multicolumn{6}{|l|}{ Riwayat DM } \\
\hline Tidak & 8 & 12 & Ref & & \\
\hline $\mathrm{Ya}$ & 48 & 44 & 1,63 & $0,612-4,376$ & 0,324 \\
\hline \multicolumn{6}{|l|}{$\begin{array}{l}\text { Riwayat penyakit jantung dan } \\
\text { pembuluh darah }\end{array}$} \\
\hline Ya & 26 & 28 & Ref & & \\
\hline Tidak & 30 & 28 & 1,15 & $0,413-1,820$ & 0,705 \\
\hline \multicolumn{6}{|l|}{ Merokok } \\
\hline Tidak & 23 & 21 & Ref & & \\
\hline Ya & 33 & 35 & 0,86 & $0,403-1,839$ & 0,699 \\
\hline \multicolumn{6}{|l|}{ Durasi Pemberian Obat } \\
\hline$<12$ Bulan & 13 & 34 & Ref & & \\
\hline$>12$ Bulan & 43 & 22 & 5,11 & $2,555-15,204$ & $<0,001$ \\
\hline \multicolumn{6}{|l|}{$\begin{array}{l}\text { Tingkat kepatuhan minum obat } \\
\text { menggunakan Morisky }\end{array}$} \\
\hline Medication Adherence Scale & 6 & 45 & Ref & & \\
\hline $\begin{array}{l}\text { Kepatuhan tingg1 } \\
\text { Kepatuhan rendah dan sedang }\end{array}$ & 50 & 11 & 28,52 & $11,657-99,702$ & $<0,001$ \\
\hline
\end{tabular}


Tabel III. Faktor Prediktor Terjadinya Stroke Berulang

\begin{tabular}{lccc}
\hline \multicolumn{1}{c}{ Variabel } & OR & $\mathbf{9 5 \%}$ CI & $\boldsymbol{P}$ \\
\hline $\begin{array}{l}\text { Durasi Pemberian Obat }>12 \\
\text { bulan }\end{array}$ & 6,03 & $2,459-12,806$ & $<0,001$ \\
$\begin{array}{l}\text { Tingkat Kepatuhan Minum } \\
\text { Obat Rendah dan Sedang }\end{array}$ & 28,52 & $12,657-88,762$ & $<0,001$ \\
\hline
\end{tabular}

Penilaian tingkat kepatuhan minum obat yang dilakukan oleh pasien, didapatkan hasil bahwa sebanyak 50 pasien dengan stroke berulang dan 11 pasien tidak berulang memiliki tingkat kepatuhan sedang dan rendah, sedangkan 6 pasien stroke berulang dan 45 pasien dengan stroke tidak berulang memiliki tingkat kepatuhan tinggi. Hal tersebut menandakan bahwa tingkat kepatuhan minum obat sedang dan rendah berhubungan dengan kejadian stroke berulang. Hasil tersebut juga didukung dari hasil perhitungan statistik yang menunjukkan nilai $\mathrm{p}<0,005$. Tingkat kepatuhan minum obat seorang pasien mempengaruhi terjadinya kejadian stroke berulang pada pasien stroke iskemik. Pasien dengan kepatuhan yang rendah dan sedang akan memiliki risiko 28 kali lebih besar untuk mengalami stroke berulang, dan pasien dengan kepatuhan tinggi memiliki kejadian stroke berulang yang rendah. Hasil tersebut sejalan dengan penelitian yang dilakukan oleh Tanja Sappok (2001), yang menyatakan bahwa kepatuhan minum obat tinggi dalam pencegahan sekunder pada pasien dengan stroke iskemik memiliki hasil yang lebih baik dibandingan dengan pasien dengan ketidakpatuhan minum obat atau yang mempunyai angka kepatuhan rendah. Usia yang lebih tinggi, defisit neurologis yang lebih parah saat masuk, dan kardioembolik stroke berkaitan dengan kepatuhan jangka panjang yang lebih baik. Pengetahuan tentang faktorfaktor penentu ini dapat membantu untuk lebih meningkatkan kualitas pencegahan stroke. Penelitian yang dilakukan Biller (2009), menyatakan bahwa, salah satu hal terpenting dalam proses pengobatan pada pasien stroke iskemik adalah tingkat kepatuhan minum obat, hal tersebut dibuktikan dengan semakin berkurangnya agregasi platelet yang ada pada pasien dengan tingkat kepatuhan yang tinggi, namun hal tersebut tidak sepenuhnya menjadi hal menentukan dalam terjadinya 
stroke berulang karena masih banyak faktor risiko mayor yang dapat menginisiasi terjadinya rekurensi stroke.

Kepatuhan minum obat merupakan suatu perilaku yang dilakukan dengan kesadaran oleh pasien untuk mematuhi dan melaksanakan rencana terapi penggunaan obat. Tingkat kepatuhan minum obat sedang dan rendah tersebut dapat terjadi karena perilaku kepatuhan tersebut dipengaruhi oleh berbagai macam faktor seperti yang dikatakan oleh Niven (2002), yaitu : pemahaman instruksi yang diberikan, latar belakang pendidikan, dorongan dari keluarga dan lingkungan sekitar dan keyakinan untuk sembuh. Selain itu kepatuhan secara keseluruhan menurut Brunner and Suddarth (2002) dapat dipengaruhi oleh demografi seperti usia, jenis kelamin, suku bangsa, status sosio ekonomi dan pendidikan, keparahan penyakit dan hilangnya gejala akibat terapi, program terapeutik seperti kompleksitas program dan efek samping yang tidak menyenangkan, psikososial seperti intelegensia, sikap terhadap tenaga kesehatan, penerimaan, atau penyangkalan terhadap penyakit, keyakinan agama atau budaya dan biaya financial dan lainnya yang termasuk dalam mengikuti regimen hal tersebut di atas juga ditemukan oleh Bart Smet dalam psikologi kesehatan. Tingkat kepatuhan rendah dan sedang tersebut akan menyebabkan terjadinya suatu keadaan tidak tercapainya suatu pola teraupetik yang teratur sesuai dengan apa yang direncanakan oleh dokter dengan hasil yang juga diharapkan dari proses teraupetik tersebut. Kepatuhan rendah dan sedang tersebut juga dapat mempengaruhi dosis efektif yang diberikan oleh dokter, dengan kata lain hal tersebut dapat menyebabkan dosis menjadi kurang maksimal dengan hasil terapi yang kurang maksimal juga, hal tersebut dapat menginisiasi terjadinya stroke berulang. Kepatuhan rendah dan sedang tersebut juga dapat mengindikasikan jika terdapat kurangnya dorongan dari pihak keluarga dan lingkungan sekitar yang mana hal tersebut berpengaruh pada kondisi pasien (Brunner and Suddarth, 2002). Penelitian Faqing Long et al. (2014) juga menyatakan bahwa edukasi yang dilakukan oleh tenaga kesehatan dan pendidikan kesehatan yang baik sangat mempengaruhi kualitan minum obat seseorang. 
Penelitian ini didapatkan hasil bahwa semua pasien mendapatkan obat antiplatelet aspirin (ASA), hal ini sesuai dengan yang direkomendasikan oleh AHA (American Heart Assosiation) yang merekomendasikan aspirin (ASA) sebagai lini pertama antiplatelet yang sudah terbukti keefektifannya. Penelitian Biller (2009) mengatakan bahwa obat antiplatelet seperti aspirin memiliki peran besar dalam pencegahan sekunder kejadian stroke. Hasil studi dari CAST (Chinese Acute Stroke Trial) menunjukkan bahwa aspirin menurunkan risiko stroke iskemik berulang dari $2,1 \%$ menjadi $1,6 \%$, namun risiko dari semua rekurensi stroke (hemoragik atau iskemik) tidak secara signifikan berkurang (CAST, 1997). Demikian pula, IST (The International Stroke Trial) menyatakan bahwa aspirin secara signifikan mengurangi tingkat rekurensi stroke iskemik dari 3,9\% menjadi $2,8 \%$.

Hal tersebut dipertegas lagi dari Antithrombotic Trialis Collaboration (ATC) yang diterbitkan tahun 2002 bahwa aspirin efektif menurunkan risiko stroke iskemik dan kejadian kardiovaskular sampai 25\%. Namun pada penggunaan obat antiplatelet aspirin juga tidak berarti bahwa pasien yang menggunakan obat antiplatelet aspirin dapat terbebas $100 \%$ dari kejadian stroke berulang. Hal tersebut dapat terjadi karena salah satu faktor yaitu adanya suatu resistensi dari aspirin. Resistensi aspirin adalah suatu keadaan dimana terjadinya efek antiplatelet yang berkurang atau tidak terjadinya efek yang berarti pada pemakaian aspirin. Ada sejumlah faktor ekstrinsik yang dapat mengaktivasi trombosit sehingga memungkinkan untuk "menimpa" efek dari aspirin. Merokok telah terbukti dapat menaikkan efek trombosis dengan cara yang tidak dapat dihambat oleh aspirin. Non-steroid Anti-Inflamasi (NSAID) seperti ibuprofen dan indometasin juga dapat mengganggu efek jangka panjang antiplatelet aspirin. Menurut Irmawati (2014), adapun faktor-faktor yang dapat mengakibatkan terjadinya resistensi aspirin ini adalah peningkatan usia, diabetes mellitus dan trigliserida plasma yang tinggi. Resistensi Aspirin ini terjadi pada 30\%-40\% pasien stroke atau penyakit pembuluh darah perifer dan dikaitkan dengan bertambahnya peningkatan $80 \%$ dalam risiko kejadian vaskular terulang selama 2 tahun periode follow up. 
Durasi pemberian obat disini untuk lebih menegaskan berapa lama pasien tersebut mengalami serangan stroke dan berapa lama pasien tersebut menggunakan antiplatelet. Dalam penelitian ini didapatkan hasil 43 pasien yang menjalankan pengobatan lebih dari 12 bulan mengalami stroke berulang. Hal tersebut menunjukkan bahwa durasi minum obat mempengaruhi terjadinya stroke iskemik berulang $(\mathrm{p}<0,005)$. Seperti yang dikatakan oleh Siswanto (2005), bahwa semakin lama durasi penggunaan obat menandakan bahwa pasien tersebut sudah lama juga menderita stroke dan dapat menjadi salah satu faktor yang dapat menyebabkan peluang terjadinya kejadian stroke berulang. Hal tersebut didukung dengan penelitian yang dilakukan oleh Adib (2009) yang menyatakan bahwa pasien yang mengalami stroke pertama dalam kurun waktu lebih dari 1 tahun memiliki peluang $25 \%$ akan mendapatkan stroke berulang. Hasil penelitian epidemiologis yang dilakukan oleh Yulianto (2011) juga menunjukkan bahwa risiko terjadinya stroke berulang sebesar $25 \%$ - $37 \%$ dalam kurun waktu 2 tahun pertama. Durasi penggunaan obat yang semakin lama tersebut menjadi salah satu faktor yang dapat mempengaruhi terjadinya stroke berulang karena pasien mulai mengalami adanya suatu kejenuhan dalam melakukan terapi minum obat secara teratur. Kejenuhan tersebut yang dapat menyebabkan pasien mulai kehilangan motivasi dan semangat untuk melakukan kegiatan terapi. Selain mengalami kejenuhan, durasi yang semakin lama juga menyebabkan banyaknya biaya yang harus dikeluarkan oleh pasien atau keluarganya dalam melakukan suatu proses pengobatan, dimana hal tersebut dapat menjadi beban pasien beserta keluarga yang dapat berpotensi menyebabkan pasien mulai mengurangi dan menghentikan proses terapi, akhirnya akan dapat menginisiasi terjadinya kejadian stroke berulang.

\section{KESIMPULAN}

Ada hubungan antara tingkat kepatuhan minum obat antiplatelet aspirin dengan kejadian stroke berulang pada pasien stroke iskemik di rumah sakit Bethesda, Yogyakarta. Pasien dengan tingkat kepatuhan rendah-sedang memiliki 
risiko serangan ulang lebih tinggi daripada pasien dengan tingkat kepatuhan tinggi.

\section{DAFTAR PUSTAKA}

Adib M., 2009, Cara Mudah Memahami dan Menghindari Hipertensi Jantung dan Stroke, Dianloka, Yogyakarta.

American Stroke Association, 2010, Guidelines for the Prevention of Stroke in Patients With Stroke or Transient Ischemic Attack.

Biller, J, 2009, Ischemic Cerebrovascular Disease. In: Biller, J., ed. Practical Neurology, Lippincott Williams \& Wilkins, USA: 459-473.

Brunner and Suddarth, 2002, Buku Ajar Keperawatan Medikal Bedah, Edisi 8, EGCG, Jakarta.

CAST (Chinese Acute Stroke Trial) Collaboration Group, 1997, CAST: Randomized Placebo-Controlled Trial of Early Aspirin Use in 20,000 Patients with Acute Ischaemic Stroke, Lancet, 349: 1641-1649.

Duke Clinical Research Institute, 2010, Adherence Evaluation After Ischemic Stroke-Longitudinal (AVAIL).

Faqing Long, Kunxiong Yuan, and Qingjie Su, 2014, Evaluation on The Compliance with Secondary Prevention and Influence Factors of Ischemic Stroke in Hainan Province, China, Sage Journals, 22 (3): 181-187.

Fitzsimmons, B., M., 2007, Cerebrovascular Disease: Ischemic Stroke. In: Brust, J., C., M., ed. Current Diagnosis \& Treatment in Neurology, McGrawHill, USA: $100-125$.

Fauci, A.S., 2008, Harrison's Principles of Internal Medicine, Volume II, 17th Edition, Mc-Graw-Hill Companies Inc, State of America: 2513-2521.

Niven, N., 2002, Psikologi Kesehatan, Penerbit Buku Kedokteran EGC, Jakarta.

Siswanto, Y., 2005, Analisis Faktor yang Mempengaruhi Stroke Berulang, Jurnal Universitas Diponegoro Semarang, http://eprints.undip.ac.id/4942/, was accesed on December 15, 2015.

World Heart Federation, 2014, Stroke. http://www.world-heartfederation.org/cardiovascular-health/stroke/

World Health Organization Stroke, 2010, Cerebrovascular Accident

Yulianto M., 2011, Mengapa Stroke Menyerang Usia Muda, Javalitera, Jogjakarta. 